\title{
A STUDY ON PREANALYTICAL ERRORS IN EDTA BLOOD COLLECTED FOR CELL COUNTING
}

\author{
Dinu Mary Raj ${ }^{1}$, Kavitha Ravi², Sankar S3 \\ ${ }^{1}$ Lab Technician, ESI Hospital, Ezhukone, Kollam. \\ ${ }^{2}$ Associate Professor, Department of Pathology, Government Medical College, Thiruvananthapuram. \\ ${ }^{3}$ Professor, Department of Pathology, Government Medical College, Thiruvananthapuram.
}

\begin{abstract}
\section{BACKGROUND}

Preanalytical errors are largely attributable to human mistakes and the majority of these errors are preventable. This study emphasises on analysing certain preanalytical quality variables such as patient's name and IP number, Specimen lost, Test order form missing, Insufficient volume, Specimen clotted, Vial exterior soiled with blood, Lysed specimen, etc. Preanalytical phase includes specimen collection, handling and processing variables, physiological variables such as the effect of lifestyle, age, gender, pregnancy and menstruation and endogenous variables such as drugs and circulating antibodies. In the last years, the preanalytical phase became more and more important in laboratory medicine and various studies have been performed and published about the possible source of errors represented by the incorrect collection and storage of specimens.

The current study is aimed to assess the quality of specimen for cell counting in EDTA blood, obtained with needle and syringe collection using rewashed glass vials.
\end{abstract}

\section{MATERIALS AND METHODS}

We did a cross sectional study for a period of five months after getting clearance from human ethical committee in the Clinical Pathology Laboratory, Medical College, Thiruvananthapuram. EDTA IP Samples received in the clinical pathology lab for cell counting were analysed.

\begin{tabular}{|c|c|c|c|}
\hline Sample & $\mathrm{cal}$ & lat & using the formula $\mathrm{n}=\frac{4 \mathrm{pq}}{\mathrm{L}^{2}}$ \\
\hline Where & $\mathrm{p}$ & $=$ & Proportion having the error. \\
\hline & $\mathrm{q}$ & $=$ & 1-p (Proportion not having the error.) \\
\hline & $\mathrm{L}$ & $=$ & $20 \%$ of P (Permissible limit of error) \\
\hline
\end{tabular}

Sample size was found to be 1900 samples based on Reference study 25. All blood specimens were collected using a hypodermic needle 22G/23G size and disposable syringes $(2 \mathrm{~mL}, 5 \mathrm{~mL})$ procured from the standard hospital purchasing process. Specimens were collected using needle and syringe and transferred to re-used, washed and dried glass vials containing EDTA powder. Samples were transported to the laboratory at room temperature from different wards. For each specimen, a quality assessment proforma was filled with the below-mentioned quality variables at the time of reception of sample. Sample analysis was done in the three-part eighteen-parameter auto-haematology analyser.

\section{RESULTS}

- A total of 1900 IP samples were studied for eight variables such as patients IP number missing, Specimen missing, Test order form missing/incomplete, Insufficient volume, Specimen clotted, Vial exterior soiled with blood, Lysed specimen, etc.

- $\quad$ Out of these 1900 samples analysed, 1408 samples showed errors. Rest of the 492 samples were proper samples.

- Among the improper samples, the variables included were Excess anticoagulant, Specimen missing, Insufficient volume, Specimen clotted, vial exterior soiled with blood and specimen lysed.

- Patient identification errors include IP number missing and test order form missing/incomplete.

- Among total 1408 error samples, 651 samples were improper samples (34.3\%) and 757 samples showed patient identification errors (39.8\%).

- Among 651 improper samples, 125 samples showed Excess anticoagulant (19.2\%), 68 sample volumes were insufficient (10.4\%), 113 samples were clotted specimens (17.4\%), 342 sample vials' exterior soiled with blood (52.5\%), and 3 samples were lysed $(0.5 \%)$

- $\quad$ Out of 757 samples that showed identification errors, 179 samples were without Patient IP number in the request form (23.6 $\%)$ and 578 samples were of incomplete test order forms (76.4\%).

\section{CONCLUSION}

1. Preanalytical errors are largely attributed to human mistakes and majority of these errors are preventable since the preanalytical phase involves much more human handling, compared to the analytical and post-analytical phases.

2. The promotion of the quality control and continuous improvement of the total testing process, including pre- and postanalytical phases, seems to be a prerequisite for an effective laboratory service.

3. In view of increasing attention focused on patient safety and the need to reduce laboratory errors, it is important that clinical laboratories collect statistics on error occurrence rates over the whole testing cycles.

\section{KEYWORDS}

Preanalytical Errors, EDTA, Blood Samples, Laboratory, Quality, Cell Counting. 
HOW TO CITE THIS ARTICLE: Raj DM, Ravi K, Sankar S. A study on preanalytical errors in EDTA blood collected for cell counting. J. Evolution Med. Dent. Sci. 2017;6(22):1788-1793, DOI: 10.14260/Jemds/2017/393

Financial or Other, Competing Interest: None.

Submission 02-02-2017, Peer Review 03-03-2017,

Acceptance 10-03-2017, Published 16-03-2017.

Corresponding Author:

Dr. Dinu Mary Raj,

Lab Technician,

ESI Hospital,

Ezhukone,

Kollam.

E-mail: dinumaryraj@gmail.com

DOI: $10.14260 /$ jemds $/ 2017 / 393$

\section{(c) (i) $(\$$}

\section{BACKGROUND}

Managing Preanalytical Variability in laboratory testing is a critical factor for ensuring accurate results. These Preanalytical errors are influenced by several factors like specimen collection, specimen handling, interfering substances and patient factors.

With an increasing number of laboratory tests requested, laboratory professionals are faced with challenges to reduce laboratory errors, improve quality of laboratory results to assure accurate diagnosis and implement initiatives to ensure health care worker safety and minimise risk of exposure to blood borne pathogens. ${ }^{1}$

The current study is aimed to assess the quality of specimen for cell counting in EDTA blood, obtained with needle and syringe collection using rewashed glass vials.

Preanalytical phase includes specimen collection, handling and processing variables, physiological variables such as the effect of lifestyle, age, gender, pregnancy and menstruation and endogenous variables such as drugs and circulating antibodies.

Preanalytical errors are largely attributable to human mistakes and the majority of these errors are preventable. This study emphasises on analysing certain preanalytical quality variables such as patient's name and IP number, Specimen lost, Test order form missing, Insufficient volume, Specimen clotted, Vial exterior soiled with blood, Lysed specimen, etc. ${ }^{1}$

Transport and storage of the test material sometimes tend to play a rather subordinate part in the preanalytical process. And there are parameters in Haematology that should be measured immediately or within a few hours after the blood is taken if correct test results are to be obtained.

The total testing process is the total process from the ordering of a test to the interpretation of a test result. The total testing process starts and ends with the patient, and can be subdivided into three distinctive phases: The preanalytical step (before the analysis), the analytical step (the actual analysis) and the postanalytical step (after the analysis).

\section{EDTA as the Anticoagulant of Choice for Haematology}

EDTA (Ethylenediaminetetraacetic acid) is the most commonly used anticoagulant in Haematology. It inhibits the clotting process by removing calcium from the blood. EDTA's most distinct characteristic is that it does not distort blood cells, making it ideal for Haematology use.

Enough EDTA must be present to prevent coagulation, but excessive amounts cause morphological changes in blood cells. $^{2}$ When K2EDTA is present in a concentration of 1.5 to
$2.0 \mathrm{mg} / \mathrm{mL}$ of blood, it does not have any significant effect on the blood count parameters. ${ }^{3}$

\section{MATERIALS AND METHODS}

We did a cross sectional study for a period of Five months after getting clearance from Human ethical committee in the Clinical Pathology Laboratory, Medical College, Thiruvananthapuram.

EDTA IP Samples received in the clinical pathology lab for cell counting were analysed.

Sample size was calculated using the formula $\mathrm{n}=\frac{4 \mathrm{pq}}{\mathrm{L}^{2}}$
Where $\mathrm{p}=$ Proportion having the error.
$\mathrm{q}=1-\mathrm{p}$ (Proportion not having the error.)
$\mathrm{L}=20 \%$ of P (Permissible limit of error)

Sample size was found to be 1900 samples based on reference study 25 .

All blood specimens were collected using a hypodermic needle 22G/23G size and disposable syringes $(2 \mathrm{~mL}, 5 \mathrm{~mL})$ procured from the standard hospital purchasing process. Specimens were collected using needle and syringe and transferred to re-used, washed and dried glass vials containing EDTA powder. Samples were transported to the laboratory at room temperature from different wards. For each specimen, a quality assessment proforma was filled with the below-mentioned quality variables at the time of reception of sample. Sample analysis was done in the threepart eighteen-parameter auto-haematology analyser.

Blood films were prepared from EDTA anticoagulated blood. The films were labelled immediately after spreading and staining was done with Leishman's stain.

\section{RESULTS}

A total of 1900 IP samples were studied for eight variables such as patients IP number missing, Specimen missing, Test order form missing/incomplete, Insufficient volume, Specimen clotted, Vial exterior soiled with blood, Lysed specimen, etc.

Out of these 1900 samples analysed, 1408 samples showed errors. Rest of the 492 samples were proper samples. (Table-1). $74.1 \%$ samples showed errors and $25.9 \%$ of samples were proper samples.

The Preanalytical variables were broadly classified into two classes- Improper sample and Patient identification error.

Among the Improper samples, the variables included were Excess anticoagulant, Specimen missing, Insufficient volume, Specimen clotted, Vial exterior soiled with blood and Specimen lysed.

Patient identification errors include IP number missing and test order form missing/incomplete.

Among total 1408 error samples, 651 samples were improper samples $(34.3 \%)$ and 757 samples showed patient identification errors (39.8\%).

Among 651 improper samples, 125 samples showed Excess anticoagulant (19.2\%), 68 sample volumes were 
insufficient (10.4\%), 113 samples were clotted specimens (17.4\%), 342 sample vials' exterior soiled with blood (52.5\%), and 3 samples were lysed (0.5\%).

Out of 757 samples that showed identification errors, 179 samples were without Patient IP number in the request form $(23.6 \%)$ and 578 samples were incomplete test order forms (76.4\%).

\section{Rejection Rate}

Among the eight preanalytical variables mentioned above, samples with Excess anticoagulant, Insufficient volume, Lysed specimen and clotted specimen were rejected and not evaluated for cell counting.

Out of 1900 samples, total rejected sample size was 309, so the rejection rate in the lab was $16.3 \%$.

In this study, majority of samples rejected were due to excess anticoagulant and clotting of blood.

\begin{tabular}{|c|c|c|}
\hline $\begin{array}{c}\text { Preanalytical } \\
\text { Variable }\end{array}$ & Observation & Method \\
\hline $\begin{array}{c}\text { Excess } \\
\text { anticoagulant }\end{array}$ & $\begin{array}{c}\text { Peripheral smear } \\
\text { examination }\end{array}$ & $\begin{array}{c}\text { Microscopic } \\
\text { verification }\end{array}$ \\
\hline $\begin{array}{c}\text { IP number } \\
\text { missing }\end{array}$ & Manual check & $\begin{array}{c}\text { Manual } \\
\text { verification }\end{array}$ \\
\hline $\begin{array}{c}\text { Specimen } \\
\text { missing }\end{array}$ & $\begin{array}{c}\text { Requisition received but no } \\
\text { specimen }\end{array}$ & $\begin{array}{c}\text { Manual } \\
\text { verification }\end{array}$ \\
\hline $\begin{array}{c}\text { Test order form } \\
\text { incomplete }\end{array}$ & Manual check & $\begin{array}{c}\text { Manual } \\
\text { verification }\end{array}$ \\
\hline $\begin{array}{c}\text { Insufficient } \\
\text { volume }\end{array}$ & $\begin{array}{c}\text { Laboratory was not able to } \\
\text { report one or more tests due } \\
\text { to insufficient volume }\end{array}$ & $\begin{array}{c}\text { Check reported } \\
\text { tests vs. } \\
\text { requisition }\end{array}$ \\
\hline $\begin{array}{c}\text { Specimen } \\
\text { clotted }\end{array}$ & $\begin{array}{c}\text { Presence of visibly clotted } \\
\text { specimen }\end{array}$ & $\begin{array}{c}\text { Visual } \\
\text { observation }\end{array}$ \\
\hline $\begin{array}{c}\text { Vial exterior } \\
\text { soiled with } \\
\text { blood }\end{array}$ & $\begin{array}{c}\text { Blood stained exterior of the } \\
\text { container }\end{array}$ & $\begin{array}{c}\text { Visual } \\
\text { observation }\end{array}$ \\
\hline $\begin{array}{c}\text { Specimen lysed } \\
\text { Manual check }\end{array}$ & $\begin{array}{c}\text { Visual } \\
\text { observation }\end{array}$ \\
\hline \multicolumn{2}{|c|}{ Table 1 } \\
\hline
\end{tabular}

\begin{tabular}{|c|c|c|}
\hline Preanalytical Errors & Number of Samples & Percentage \\
\hline Present & 1408 & 74.1 \\
\hline Absent & 492 & 25.9 \\
\hline Total & $\mathbf{1 9 0 0}$ & $\mathbf{1 0 0}$ \\
\hline \multicolumn{3}{|c|}{ Table $\mathbf{2}$} \\
\hline
\end{tabular}

\begin{tabular}{|c|c|c|}
\hline Improper Samples & Frequency & Percentage \\
\hline Excess anticoagulant & 125 & 19.2 \\
\hline Insufficient volume & 68 & 10.4 \\
\hline Specimen clotted & 113 & 17.4 \\
\hline Vial exterior soiled with blood & 342 & 52.5 \\
\hline Specimen lysed & 3 & 0.5 \\
\hline Total Table 3 \\
\hline \multicolumn{2}{|c|}{$\mathbf{6 5 1}$} & $\mathbf{1 0 0 . 0}$ \\
\hline
\end{tabular}

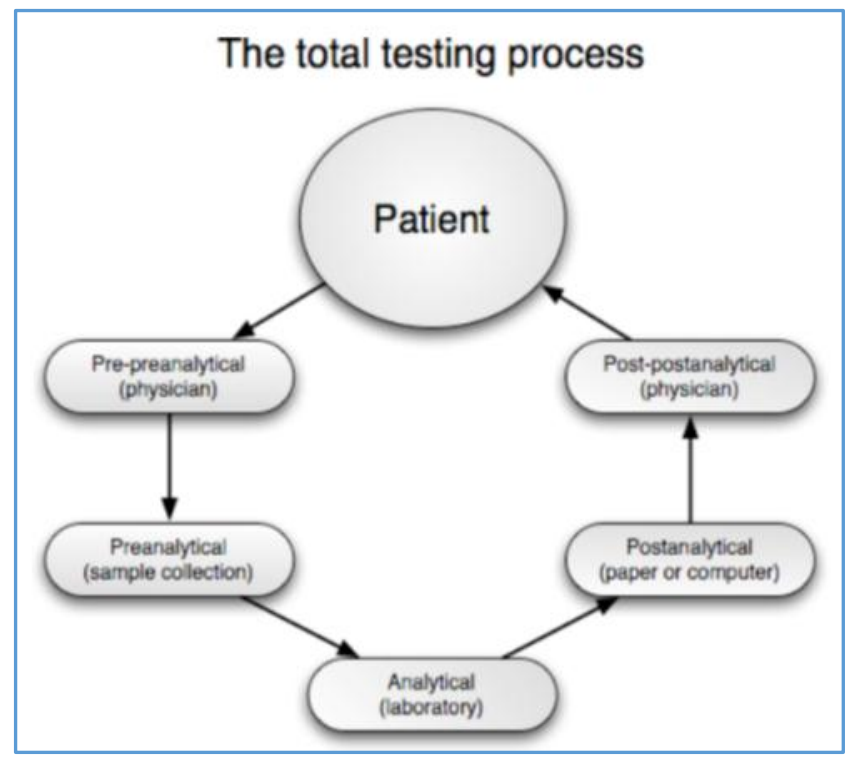

Figure 1

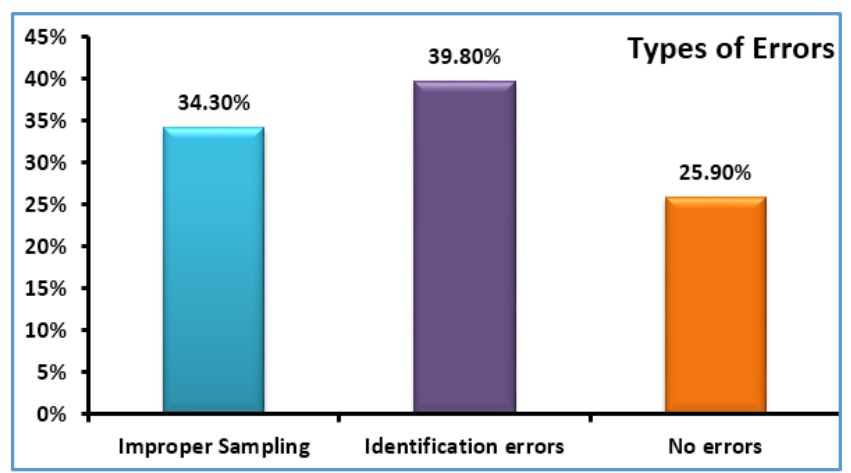

Figure 2

\section{DISCUSSION}

Issues such as proper patient and specimen identification, appropriateness of test requests, accuracy in blood drawing, Specimen handling and transportation can strongly affect the test quality.

Data collection for some performance measures such as Customer satisfaction, Turnaround time, Patient identification, Specimen acceptability, Proficiency testing, Critical value reporting, etc. should be done periodically, and suggestions should be made to improve the patient safety by reducing these errors.

It was observed that 342 out of 1900 samples collected using needle and syringe showed soiling of the exterior of the container with patient blood. Since the specimen containers pass through several laboratory and non-laboratory personnel before analysis and final disposal, soiled exteriors could pose potential blood exposure to health care workers. Several blood borne pathogens (HBV, HCV, and HIV) are transmitted through blood exposure. In addition, reports indicate that HBV virus can survive for at least one week in dried blood on environmental surfaces or contaminated needles and instruments.

Previous studies have shown that collection with evacuated blood collection method can avoid the soiling of blood over the vial exterior, thereby avoiding the blood exposure to the laboratory and non-laboratory personnel. ${ }^{4}$

113 samples were clotted out of 1900 total samples studied. Since increasing number of cell counts automated 
haematology analysers, microclots in whole blood could pose a major risk of erroneous results and analyser breakdown.

It is easier to detect a microfibrin clot in serum samples, but clot identification in whole blood may be difficult. Presence of clots in EDTA samples is primarily due to increased blood to additive ratio or improper mixing of the sample after collection.

Clotted specimens referred for coagulation testing and complete blood count should not be processed and additional sample should be requested.

We can reduce this error by using commercially available EDTA bottles or evacuated blood collection system with EDTA spray dried coating or EDTA bottles can be prepared in the laboratory itself and can be sent to the collection area and can be more economical.

\section{Specimen Identification - Related Errors}

Variables such as IP number missing (179/1900) and incomplete test order form $(578 / 1900)$ are included under identification errors. $39.8 \%$ of total samples showed identification errors.

\section{Incomplete Test Order Forms}

Hand written, paper requisitions usually accompany the specimen and most of the requisition forms are with name and age only, creating lot of confusions in sample identification.

If we keep a printed request form for a particular lab and make it mandatory to fill the form completely with all patient details, we can reduce the identification errors to some extent. If doubts regarding the proper identification of the specimen persist, laboratory staff must request an additional sample. According to recommendations of CAP and JCAHO sample relabeling by laboratory personnel, Clinical staff or third parties is strongly discouraged. 5 When a second specimen is not available the sample must not be processed and test results should be replaced with a comment "analysis cannot be performed due to identification errors". 6

Introduction of a hospital computerised order entry system can eliminate some errors such as wrong patient name or care unit. ${ }^{7}$

On the labels this should include at least surname and forename or initials, hospital number, date of birth, and date and time of specimen collection. The same information must be given on the request form, together with ward or department, name of requesting clinician, and test(s) requested. 8

When relevant, a biohazard warning also must be affixed to the container and to the request form. If automated patient identification is available, both the label and the request form should be bar-coded with the relevant data.

\section{The Test Order}

Laboratory tests are usually ordered electronically (computer) or in writing (paper requisition). This information is conveyed through written or computer order entry. Online computer input is the most error free means of requesting laboratory tests.

Computerised laboratory information systems (LIMS), common in today's laboratories, are used to generate requisitions with the number of tubes and type of tubes required for collection. ${ }^{9}$
All specimens must be clearly labelled. Pre-printed barcode labels applied after proper patient identification and after the specimen is collected, avoid transcription, preanalytic errors. Frequently the laboratory receives request for "add-ons". These are additional tests requested to be performed on a specimen that has previously been collected. Problems are encountered when the specimen is not the proper type for the add-on requested test. This is usually due to the presence or absence of a particular anticoagulant or additive. All add-on requests must be documented. ${ }^{9}$

Medicolegal concerns include proper identification of the patient, proper labelling of the specimen, patient consent issues, patient privacy issues and chain of custody. Laboratories should have clearly written policies for the above issues. In addition, there should be policies on what to do when a patient refuses to have blood drawn, what to do if a patient was not able to be drawn, what to do if a patient is unavailable and how to deal with a combative patient.

The Health Insurance Portability and Accountability Act (HIPAA) addresses the security and privacy of health data and protects the confidentiality of all patient record information including all laboratory data. Employees must be trained to comply with HIPAA 9 .

\section{Samples with Excess Anticoagulant}

125 samples got rejected as a result of excess anticoagulant. Major reason for excess anticoagulant in the sample is that EDTA powder is sprinkled to the bottle without any quantity measurements or blood may not be added to the sufficient volume to attain its correct concentration.

Smears made from EDTA tubes that sit at room temperature for more than 5 hours often have unacceptable artefact of the blood cells (echinocytic RBCs, spherocytes, and necrobiotic leucocytes). ${ }^{10}$ If a tube is not filled to its full volume of draw, the additive to blood specimen ratio is affected, resulting in too high a concentration of EDTA. ${ }^{11}$ In high concentrations, EDTA causes red cells to shrink because of hypertonicity of the plasma with increased ionic concentration and may create artefacts that make RBC morphology difficult to interpret.

Pseudothrombocytopenia can complicate an accurate determination of a platelet count in a patient with an underlying thrombocytopenic disorder.12 Platelet clumping may be a result of poor mixing - too little and/or too late, and/or a small, whole blood clot or very small fibrin clots in the EDTA-anticoagulated specimen. Additionally, the improper collection of the blood sample may cause thrombin release and a falsely low platelet count due to platelet aggregation. ${ }^{13}$ Clotting can also be the result of insufficient EDTA, usually caused by overfilling the vacuum tube, or poor solubility of EDTA (most commonly disodium EDTA).

It is important to be able to distinguish between reduced platelet counts due to technique related variables or due to a patient's medical condition. ${ }^{14,15}$

Platelet clumping is a phenomenon occurring due to EDTA dependent antibodies against platelet surface glycoproteins and may result in a falsely low platelet count. Collection of samples for platelet counting into sodium citrate can sometimes eliminate this. ${ }^{16}$ 


\section{Samples with Insufficient Volume}

68 samples were rejected due to insufficient volume out of 1900 samples.

Laboratory should clearly specify within its operating procedures, the minimum sample volume required to complete the analysis. The minimum specimen volume may vary according to the type and number of analyses.

Acquisition of lower than the recommended volume of blood in the vial could result in higher concentration of EDTA per $\mathrm{mL}$ of blood than that recommended by CLSI. This in turn may lead to cell shrinkage and lower MCV. ${ }^{4}$

\section{Lysed Specimen}

3 samples, out of 1900 samples were rejected due to haemolysis.

Haemolysis is the breakage of the red blood cell's (RBC's) membrane, causing the release of the haemoglobin and other internal components into the surrounding fluid. Haemolysis is visually detected by showing a pink to red tinge in serum or plasma. Haemolysis can occur from two sources:

- In-vivo haemolysis may be due to pathological conditions, such as autoimmune haemolytic anaemia or transfusion reaction. ${ }^{17}$

- In-vitro haemolysis may be due to improper specimen collection, specimen processing, or specimen transport.

\section{Specimen Collection}

- An improper choice in the venepuncture site, such as drawing from a distal site to the antecubital region of the arm rather than drawing from an antecubital site, has been shown to result in more haemolysis.

- Prolonged tourniquet time causes the interstitial fluid to leak into the tissue and cause haemolysis. ${ }^{18}$

- Cleansing the venepuncture site with alcohol and not allowing the site to dry may cause haemolysis. ${ }^{19}$

- An improper venepuncture, indicated by a slow blood flow, may indicate occlusion due to the lumen of the needle being too close to the inner wall of the vein, causing haemolysis. ${ }^{20}$

- The use of a small-bore needle, resulting in a large vacuum force applied to the blood, may cause shear stress on the red blood cells, causing them to rupture. ${ }^{17}$

- The use of a large bore needle may result in a much faster and more forceful flow of blood through the needle, resulting in haemolysis. 17,21

- Transferring into a tube by pushing down on the syringe plunger in order to force blood into a tube may cause haemolysis, as well as create a positive pressure in the tube which may cause the stopper to come off.

\section{Specimen Processing}

- Vigorous mixing or shaking of a specimen may cause haemolysis.

- Not allowing the serum specimen to clot for the recommended amount of time can result in fibrin formation in the serum. The use of applicator sticks to dislodge the fibrin may cause rupture of RBCs, resulting in haemolysis. ${ }^{17,22}$

- Exposure to excessive heat or cold can cause RBC rupture and haemolysis. ${ }^{9}$

\section{Specimen Transport}

- Mechanical trauma during transport resulting in haemolysis

\section{Corrective Actions}

- Redraw the specimen.

- The most common sites to draw from are the median cubital, basilic, and cephalic veins from the antecubital region of the arm.

- The choice of the needle gauge size is dependent on the patient's physical characteristics and the amount of blood to be drawn. The most commonly used sizes are 22-23G. Avoid using a needle that is too small or too large.

- Without touching, allow the venepuncture site to air dry.

- Avoid drawing the syringe plunger back too forcefully when collecting blood with a needle and syringe.

- Ensure all blood collection assemblies are fitted securely, to avoid frothing.

- Gently mix the blood additive specimens thoroughly.

- Most of these preanalytical errors can be reduced by using closed collection system such as evacuated blood collection system with plastic tubes with EDTA spray dried coating.

\section{Specimen Rejection}

In this study, $16.3 \%$ of samples got rejected due to the reasons like excess anticoagulant, clots, haemolysis, and insufficient volume.

Specimen rejection is not only costly and time consuming, but may cause harm to the patient. It is therefore essential to thoroughly train staff in all aspects of specimen collection, transportation and processing. ${ }^{23}$

\section{Blood Storage and Preservation}

During storage, concentration of a blood constituent in the specimen may change as a result of various processes, including adsorption to glass or plastic tubes, protein denaturation, evaporation of volatile compounds, water movement in the cells resulting in haemoconcentration of serum and plasma, and continuing metabolic activities of leucocytes and erythrocytes. These changes occur, though to varying degree, at ambient temperature and during refrigeration or freezing.

\section{Policies and Procedures}

It is essential to establish institution-specific phlebotomy policies and procedures that include: personal standards with qualifications, dress code and evaluation procedures; safety protocols including immunisation recommendations, universal precautions, needle stick and sharps information, personal protective equipment; test order procedures; patient identification, confidentiality and preparation and documentation of problems encountered during blood collection; needle stick site selection and areas to be avoided; anticoagulants required and tube colour, order of draw; special requirements for patient isolation units and specimen transport. The laboratory should have available all CDC, CAP, NCCLS, OSHA and JCAHO guidelines and other government regulations pertaining to laboratory testing. ${ }^{23}$

The Occupational Safety and Health Administration (OSHA: Blood borne pathogens standard) concluded that the 
best practice for prevention of needle stick injuries following phlebotomy is the use of a sharp with engineered sharp injury protection (SESIP) attached to the blood tube holder and the immediate disposal of the entire unit after each patient's blood is drawn.

Information on exposure prevention can be found on the Exposure Prevention Information Network (EPINet), a database coordinated by the international Healthcare Worker Safety Center at the University of Virginia. ${ }^{23}$

OSHA further mandates that employers make available, closable puncture resistant, leak proof sharp containers that are labelled and colour coded. The containers must have an opening that is large enough to accommodate disposal of the entire blood collection assembly

\section{CONCLUSION}

Preanalytical errors are largely attributed to human mistakes and majority of these errors are preventable since the preanalytical phase involves much more human handling, compared to the analytical and post-analytical phase. The promotion of the quality control and continuous improvement of the total testing process, including pre- and post-analytical phases seems to be a prerequisite for an effective laboratory service.

\section{REFERENCES}

[1] Narayanan S. The preanalytic phase. An important component of laboratory medicine. Am J Clin Pathol 2000;113(3):429-52.

[2] National Committee for Clinical Laboratory Standards. Tubes and additives for venous blood specimen collection: approved standard. $5^{\text {th }}$ edn. Document H1A5. Wayne, PA: NCCLS, 2003.

[3] Lewis SM, Stoddart CT. Effects of anticoagulants and containers (glass and plastic) on the blood count. Lab Pract 1971;20(10):787-92.

[4] Ashavaid TF, Dandekar SP, Khodaiji S, et al. Influence of method of specimen collection on various preanalytical sample quality indicators in EDTA blood collected for cell counting. Indian J Clin Biochem 2009;24(4):356-60.

[5] College of American Pathologists. Laboratory accreditation program. Hematology-coagulation checklist 2006. Available at: http://www.cap.org/apps/docs/laboratory_accreditat ion/checklists/hematolog_coagulation_april2006. pdf. Accessed April 20, 2007.

[6] Lippi G, Banfi G, Buttarello M, et al. Recommendations for detection and management of unsuitable samples in clinical laboratories. Clin Chem Lab Med 2007;45(6):728-36.
[7] Carraro P, Plebani M. Errors in a stat laboratory: types and frequencies 10 years later. Clin Chem 2007;53(7):1338-42.

[8] Joint Commission on Accreditation of Healthcare Organization 2007. Laboratory Services National Patient Safety Goals. Available at: http://www.jointcommission.org/PatientSafety/Natio nalPatientSafetyGoals/07_lab_npsgs.htm. Accessed November 14, 2006.

[9] Boyanton BL, Blick KE. Stability studies of twenty-four analytes in human plasma and serum. Clin Chem 2002;48(12):2242-7.

[10] Rodak BF. Diagnostic hematology. Philadelphia, PA: W. B. Saunders Company, 1995.

[11] Lampasso JA. Error in hematocrit value produced by excessive ethylenediaminetetraacetate. Am J Clin Pathol 1965;44(1):109-10.

[12] Forscher CA, Sussman II, Friedman EW, et al. Pseudothrombocytopenia masking true thrombocytopenia. Am J Hematol 1985;18(3):313-7.

[13] Kjeldsberg CR, Hershgold EJ. Spurious thrombocytopenia. JAMA 1974;227(6):628-30.

[14] Evans V. Platelet morphology and the blood smear. J Med Technol 1984;1:689-95.

[15] Shreiner DP, Bell WR. Pseudothrombocytopenia: manifestation of a new type of platelet agglutinin. Blood 1973;42(4):541-9.

[16] Practical-Haemostasis.com A Practical Guide to Laboratory Haemostasis.

[17] Lewis SM. Dacie and Lewis Practical Hematology. 10th edn. Elsevier ISBN: 978-0-443-06660-3.

[18] Lemery LD. Oh, No! It's hemolyzed! What, why, who, how? Advance for medical laboratory professionals, 1998:24-5.

[19] Burns ER, Yoshikawa N. Hemolysis in serum samples drawn by emergency department personnel versus laboratory phlebotomists. Lab Med 2002;33(5):37880.

[20] NCCLS Document H3-A4. Procedures for the collection of diagnostic blood specimens by venipuncture; approved standard. $4^{\text {th }}$ edn. Wayne, PA: National Committee for Clinical Laboratory Standards, 1998.

[21] Sharp MK, Mohammad SF. Scaling of hemolysis in needles and catheters. Ann Biochem Engineer 1998;26(5):788-97.

[22] Garza D, Becan-McBride K. Phlebotomy handbook: blood collection essentials. $5^{\text {th }}$ edn. Stamford, CT: Appleton \& Lange, 1999:227-52.

[23] Henry's clinical diagnosis and management by laboratory methods. 22nd edn. Saunders Company, 2011. 